\title{
Gramsci, educação e escola unitária
}

\author{
Marcos Francisco Martins ${ }^{1}$ \\ ORCID: 0000-0002-8220-2030
}

\section{Resumo}

Este artigo é produto de pesquisa sobre fundamentos da educação e apresenta os resultados de investigações sobre as contribuições de Antonio Gramsci (1891-1937). Este texto dá sequência a outras publicações sobre aspectos específicos do legado do autor italiano, mas aqui sintetizando as formulações que produziu, especificamente, sobre educação e escola, com vistas a averiguar sua identidade teórico-metodológica. Na primeira parte do texto, encontram-se dados biográficos e as especificidades dos escritos de Gramsci, e em seguida, há a explicitação de sua concepção de ser humano, para melhor compreender a principal contribuição que deixou sobre o nível básico de ensino: a escola unitária, apresentada na parte final da estrutura textual. A metodologia empregada foi a da pesquisa bibliográfica, que se desenvolveu principalmente pela análise dos cadernos miscelâneos e especiais de Gramsci, particularmente o 1 e o 4, e o 12 e o 22, porque são nesses escritos da maturidade que o comunista italiano mais detidamente tratou de educação e de escola. Além dos "cadernos do cárcere" e de cartas de Gramsci, textos de destacados comentadores também foram averiguados, com o objetivo de bem detectar a concepção do autor em questão sobre a escola básica. A conclusão é que as formulações sobre educação e escola apresentadas são expressões atualizadas do legado do marxismo originário e, portanto, não podem ser confundidas com concepções liberais, que implicaram propostas educacionais estranhas à escola unitária.

\section{Palavras-chave}

Antonio Gramsci (1891-1937) - Escola unitária - Fundamentos da educação - Marxismo originário.

1- Universidade Federal de São Carlos (UFSCar), Sorocaba, São Paulo, Brasil. Contato: marcosfranciscomartins@gmail.com. 


\section{Gramsci, education and unitary school}

\section{Abstract}

This paper is the product of research on the fundamentals of education; it presents the results of investigations on the contributions of Antonio Gramsci (1891-1937). This text follows on from other publications on specific aspects of the Italian author's legacy, but here summarizing the formulations he produced, specifically on education and school, to ascertain his theoretical-methodological identity. In the first part of the text, there are biographical data and the specifics of Gramsci's writings, which are followed by an explanation of his conception of human being, to better understand the main contribution he left on the basic level of education: the unitary school, presented in the final part of the textual structure. Bibliographic research was the utilized methodology, which was developed mainly by the analysis of Gramsci's miscellaneous and special notebooks, particularly 1 and 4, and 12 and 22, because in these maturity writings the Italian communist most carefully dealt with education and school. In addition to the "prison notebooks" and letters by Gramsci, texts by prominent commentators were also investigated, to detect the author's concept in question about the basic school. The conclusion is that the presented formulations on education and school are up-to-date expressions of the legacy of original Marxism and, therefore, cannot be confused with liberal conceptions, which implied educational proposals foreign to the unitary school.

\section{Keywords}

Antonio Gramsci (1891-1937) - Unitary school - Fundamentals of education - Original Marxism.

\section{Introdução}

Este artigo é resultante de pesquisa de tipo bibliográfica. Foram consultados textos da maturidade de Gramsci e de alguns renomados comentadores de seu legado. Particularmente, são trabalhados de maneira mais detida os seguintes Cadernos de Gramsci: a) 1 (1929 e 1930) - Miscelâneo; b) 4 (1930 a 1932) - Miscelâneo, em grande parte retomado no Caderno 12; c) 12 (1932) - Especial: "Apontamentos e notas dispersas para um grupo de ensaios sobre a história dos intelectuais”; d) 22 (1934) - Especial: "Americanismo e fordismo".

A primeira parte contém apontamentos biográficos de Gramsci, considerações sobre as especificidades de seus escritos e as dificuldades de interpretá-los, uma vez que o comunista da Sardenha nunca escreveu um livro, mas há vários livros a ele atribuídos.

Nas partes seguintes, encontram-se a exposição sobre a concepção educativa de Gramsci e a proposta de educação escolar que formulou para o nível básico: a escola unitária. 
É posicionada a escrita neste artigo, pois nela há uma leitura marxista de Gramsci, diferente de outras, por exemplo, das liberais, como a de Bobbio (cf. MARTINS, 2008).

Como o texto trata de autor em voga hoje no Brasil, porque é alvo preferencial de crítica da chamada "nova direita", bem como dos neoconservadores e fundamentalistas religiosos, que são base de apoio ao governo do Presidente Jair Bolsonaro, este artigo pode interessar a amplo público, de neófitos a especialistas em Gramsci.

\section{Apontamentos sobre biografia e particularidades dos escritos de Gramsci}

Quando se está a discutir e/ou a apresentar o legado do comunista italiano a leitores iniciantes nos textos que ele escreveu, é sempre importante informar que Gramsci nunca escreveu um livro, mas há vários livros com seus escritos.

Antonio Gramsci nasceu em 22 de janeiro de 1891, em Ales, na Sardenha, região italiana empobrecida e agrária à época ${ }^{2}$. Foi militante político e sindical, interessado em cultura e contribui com o avanço do conhecimento na filosofia e em várias áreas das ciências humanas e sociais. Ex-integrante do Partido Socialista Italiano (PSI) e um dos fundadores do Partido Comunista Italiano (PCI), foi jornalista e editor. Gostava de filologia ${ }^{3}$, tanto que se tornou estudante universitário na Faculdade de Letras de Turim ${ }^{4}$, embora não tenha terminado o curso. Crítico do modelo escolar do tempo em que viveu, criou iniciativas educacionais (JESUS, 2005) mesmo em condições adversas, por correspondência e no cárcere, inclusive.

Principal crítico e mártir do fascismo italiano, Gramsci foi militante marxista revolucionário ímpar e intelectual que demonstrou a genialidade de suas elaborações em difíceis condições pessoais (não passava de 1,5m de estatura e tinha sérios problemas de saúde) e de vida (quando se mudou para Turim para estudar, abriu mão de comida para comprar livros, com os parcos recursos que recebia da bolsa de estudos). Foi um dos líderes do movimento de ocupação de fábricas no "Biênio Vermelho" italiano (1919 e 1920, momento de efervescência revolucionária na Europa pós-Revolução Russa e I Guerra Mundial), sustentado na articulação dos Conselhos de Fábrica, um tipo de organização operária, que procurou traduzir para a realidade italiana os sovietes russos. Em visita à Rússia, em 1922, representando o PCI, conheceu a violinista Julia Schucht (1896-1980), que foi sua esposa. Com ela teve dois filhos, mas sequer conheceu um deles, Giuliano (1926-2007); só conviveu por pouco tempo com Délio (1924-1982), o mais velho. Quando foi preso, mesmo contando com a imunidade parlamentar (Deputado Comunista de Veneza), o promotor fascista Michele Isgrò, ao proferir a sentença de 20 anos, 4 meses e 5 dias de prisão, disse: "É preciso impedir que este cérebro funcione durante 20 anos" (COUTINHO, 1999, p. 78). Ficou preso de 8/11/1926 a 27/04/1937.

0 legado teórico e político deixado por Gramsci é dos mais extensos e nele se destacam contribuições como reavivar o marxismo, com a perspectiva histórica e dialética, contra as

\footnotetext{
2- Sobre a biografia de Gramsci, cf. Fiori (1979), Maestri e Candreva (2001) e Lepre (2001).

3 -"Amor às letras"; estudo dos aspectos que identificam uma língua, principalmente os textos que a documentam.

4- Em relação à estada de Gramsci em Turim, cf. Dias (2000).
} 
leituras economicistas e mecanicistas, enfatizando a práxis; produzir nova interpretação ao legado de Maquiavel, que o ajudou a interpretar o processo de criação tardia de Estados Nacionais, particularmente o italiano; rebater um dos principais idealistas europeus da época, Benedeto Croce (um "novo Hegel”); produzir inovadora interpretação do Estado ("Estado = sociedade civil + sociedade política5 , isto é, hegemonia revestida de coerção" - Cad. 6, § 88 - GRAMSCI, 2000b, p. 244), ampliando os conceitos até então difundidos, mormente no campo marxista; formular inovadoras interpretações de Pirandelo e Dante, bem como de folhetins estrangeiros que entravam na Itália; reinterpretar a ideologia como concepção de mundo originária da hegemonia resultante da luta de classes; criticar modelos escolares tradicionais e de inspiração nova (construtivistas), formulando proposta inovadora de escola básica, a escola unitária. Enfım, contribuiu para avançar o conhecimento no âmbito da Filosofia, Pedagogia, Sociologia, Ciência Política, Filologia e História, entre outras áreas.

Parte desse legado está registrada em escritos da juventude e da maturidade de Gramsci: textos para jornais, com os quais contribuiu e dirigiu; críticas literárias; reflexões sobre as organizações partidárias e sindicais; análises de conjuntura da Itália e da Europa, para citar alguns. No cárcere, redigiu cartas à família, a amigos e companheiros de militância, e cadernos com anotações variadas para posterior sistematização e publicação, que não teve tempo de fazer em vida. Os escritos mais famosos são os “Cadernos do cárcere”.

Os "Cadernos" começaram a ser escritos em 8 de fevereiro de 1929, dois anos depois da prisão, por causa da proibição fascista. Autorizado a escrever no cárcere, a produção se estendeu até meados de 1935, com trabalho intermitente, às vezes paralisado por problemas de saúde. Foram 33 cadernos brochura de capa dura preenchidos por Gramsci, os quais a diretoria da prisão permitiu a ele receber de familiares e amigos, juntamente com alguns livros. Entre eles estão 4 cadernos com exercícios de tradução, ainda não publicados, e 29 com apontamentos sobre diversos temas. Ao todo, os cadernos ocupam cerca de 2500 páginas impressas.

Com a morte de Gramsci, a cunhada, Tatiana Schucht, que o atendia no cárcere, resgatou os cadernos e os numerou em romano, de I a XXXIII, incluindo os de tradução, mas sem se preocupar com datação ou tematização. Gramsci escrevia em vários cadernos ao mesmo tempo e os reescrevia. Ele mesmo fez uma divisão: "cadernos miscelâneos", que guardam notas sobre temas variados (Cadernos de 1 a 9, 14, 15 e 17) e "cadernos especiais", geralmente mais tardios, nos quais Gramsci agrupou assuntos específicos de cadernos miscelâneos, por vezes reproduzindo parágrafos, com poucas alterações, fundindo-os ou dando-lhes novas redações (Cadernos de 10 a 13, 16, 18, 19 e 20 ao 29). Considerando o prefácio de Marx à 2a edição de $O$ capital (MARX, 1999), pode-se dizer que os "miscelâneos" expressam o método de pesquisa de Gramsci e os "especiais”, certa síntese expositiva até onde ele conseguiu avançar, pois morreu sem revisar os textos para publicá-los.

As primeiras publicações dos cadernos foram feitas a partir da edição de Palmiro Togliati e Felice Platone. Eles agruparam vários excertos dos cadernos por temas e seguiu-se a numeração que Tatiana Schucht lhes atribuiu. Entre o final da década de 1940 e início

5- Sobre a concepção de Estado em Gramsci, cf. Buci-Glucksmann (1980), Semeraro (1999) e Bianchi (2008). 
da de 1950, foram publicados seis volumes, identificados pelos estudiosos de Gramsci como "Edição temática".

Essa primeira edição dos cadernos contribuiu para a divulgação inicial do pensamento gramsciano. Todavia, malgrado a advertência presente nesses textos, eles induziram muitos a imaginar que Gramsci produziu seis livros no cárcere sobre temas diversos, o que é incorreto. Além disso, importa destacar que a edição feita por Togliati Platone continha recortes sensórios, tanto assim que numa carta ao Secretário Geral da Internacional Comunista, Geórgi Mikhaïlov Dimítrov, de 25/04/1941, Togliatti diz:

[...] os cadernos de Gramsci, que já estudei cuidadosamente em quase sua totalidade, contêm materiais que só podem ser utilizados depois de uma cuidadosa elaboração. Sem esse tratamento, o material não pode ser utilizado, e, aliás, algumas partes do mesmo, se forem utilizadas na forma em que se encontram atualmente, poderiam não ser úteis ao partido [...] esse material deva permanecer em nosso arquivo, para ser aqui elaborado. [É questão de] segurança organizativa [...] que tudo seja utilizado conforme a finalidade e do modo como é necessário. (TOGLIATTI apud COUTINHO, 1999, p. 22).

A edição temática chegou ao Brasil na década de 1960 pela editora Civilização Brasileira, sob responsabilidade de Ênio Silveira. Apesar de pouco sucesso editorial, foi por ela que Gramsci ganhou repercussão nos meios culturais e políticos nacionais, pois até então era praticamente desconhecido no País, a não ser por menções esparsas na imprensa socialista que, sobretudo, tratavam do martírio por ele vivido nas prisões fascistas.

Contudo, uma nova edição dos textos carcerários de Gramsci foi finalizada em 1975 pelo cuidadoso trabalho de edição coordenado por Valentino Gerratana, que superou a “edição temática”. Nesta edição foram publicados 29 Cadernos (com exceção dos 4 com exercício de tradução), organizados cronologicamente, algo difícil de fazer, porque Gramsci escrevia em vários cadernos ao mesmo tempo. Cada um dos parágrafos foi numerado e, no último volume dessa edição, conhecida mundialmente como "edição crítica”, Gerratana disponibilizou o aparato crítico dos cadernos, nos quais os descreve pormenorizadamente.

A edição produzida por Gerratana enfrentou críticas ${ }^{6}$, mas contribui significativamente para o avanço dos estudos sobre o legado de Gramsci. Ele dividiu os textos presentes nos cadernos em "A", "B" e "C". Como explica Coutinho na "Introdução" ao primeiro volume da mais recente edição dos "Cadernos do cárcere” no Brasil, por ele organizada:

Os textos A são os que Gramsci redigiu nos "cadernos miscelâneos" e depois retomou ou reagrupou (literalmente ou com modificações, maiores ou menores) em textos "C”, todos eles - com exceção de três notas presentes no caderno 14 - contidos nos "cadernos especiais"; os textos B, por sua vez, são aqueles de redação única, que aparecem sobretudo nos "cadernos miscelâneos", mas também, em um número menor de casos, em alguns "cadernos especiais". [...] os "cadernos especiais", todos mais tardios, são em sua esmagadora maioria elaborados a

\footnotetext{
$\mathbf{6}$ - "Gianni Francioni fomulara objeções à 'edição Gerratana', relativas sobretudo ao ordenamento cronológico nela proposto [...] Posteriormente [...] radicalizou suas objeções, chegando até mesmo à explícita proposição, por ocasião da discussão sobre a 'edição nacional, de uma nova edição dos Cadernos substancialmente diversa daquela de Gerratana" (COUTINHO, 1999, p. 29).
} 
partir de uma retomada de materiais já presentes nos "cadernos miscelâneos", ou seja, de uma conversão de textos A em textos C. (COUTINHO, 1999, p. 12).

É essa versão dos cadernos - “edição crítica” -, organizada na década de 1970 por Gerratana, encarregado para essa tarefa pelo Instituto Gramsci, que é mundialmente citada.

Todavia, no Brasil, a Civilização Brasileira produziu, no final da década de 1990 e início da década de 2000, uma nova edição dos cadernos, sob a responsabilidade editorial de Carlos Nelson Coutinho, Marco Aurélio Nogueira e Luiz Sérgio Henriques. Ela articula a "edição temática", a "edição crítica" e as sugestões críticas a elas, como a de Gianni Francioni (1984). Procura resgatar o "método de pesquisa" de Gramsci, presente nos cadernos miscelâneos, e o "método de exposição", expresso nos Cadernos Especiais. Além disso, essa edição trouxe dois volumes com as cartas, bem como escritos políticos produzidos da juventude (antes do encarceramento), em dois volumes também. São seis volumes ao todo com os cadernos especiais, com textos " $\mathrm{C}$ " e "B" na íntegra, acompanhados dos excertos temáticos presentes nos cadernos miscelâneos, "Índice dos Cadernos", "Índice temático" e "Aparato crítico". É uma importante contribuição aos estudos e pesquisas de Gramsci em língua portuguesa, facilitando o acesso e a compreensão da obra do revolucionário de Sardenha.

Por serem escritos “abertos”, não sistematizados para a publicação, é necessário lêlos em coligação com a conjuntura vivida por Gramsci, com a militância que desenvolveu e com os sujeitos com quem dialogou ${ }^{7}$. Embora fragmentários, guardam coerência política, ideológica e teórica, e isso pode ser observado ao fazer a leitura marxista do legado que deixou, concebendo-o como uma totalidade, articulada pelos conceitos de classe e de práxis com vistas a produzir uma nova civilidade, superando a vigente no modo de produção capitalista.

\section{A educação em Gramsci}

A escrita de Gramsci não é difícil de compreender, porquanto guarda clareza e objetividade nos posicionamentos que apresenta e nos conceitos que emprega, formula ou reformula. Veja-se, por exemplo, o caso da educação. Ao perguntar o que ela é, para Gramsci é todo e qualquer processo de formação humana, desenvolvido para tornar o ser humano atual à sua época, isto é, processo que o faz ser o que é em todas as dimensões que o identificam (objetivas e subjetivas) e que estão sujeitas a ganhar determinado perfil de acordo com a correlação de forças sociais presente no contexto vivido.

Mas, sem dúvida, há complexidades nos textos de Gramsci. Uma delas reside no entendimento que ele tem da posição da educação na totalidade histórica da vida social, o que não é simples de descrever, compreender e analisar. Para ele, a educação não é mecânico reflexo da estrutura social, pois educação e estrutura social mantêm entre si relação dialética.

Se a educação se identifica com os processos de formação humana, para bem definila é preciso identificar o que é e como se constitui o ser humano.

7- Galastri (2015) apresenta alguns autores que influenciaram Gramsci e com os quais ele dialogou. 
Para Gramsci, o humano é ser de relações, ser práxico e histórico, e não ser metafísico.

A afirmação de que a "natureza humana" é o "conjunto das relações sociais" é a resposta mais satisfatória porque inclui a idéia do devir: o homem "devém", transforma-se continuamente com as transformações das relações sociais; e, também, porque nega o "homem em geral”: [...] as relações sociais são expressas por diversos grupos de homens que se pressupõem uns aos outros, cuja unidade é dialética e não formal. (Cad. 7, § 35 - GRAMSCI, 1999, p. 245).

Não há, para Gramsci, um sujeito metafísico a intervir na realidade e na formação do ser humano que não seja ele próprio, embora alguns aleguem ser Deus, outros a estrutura social ou linguística e/ou a história como racionalidade, que se constitui como pano de fundo para a ação humana, como afırmava Hegel. Diz Gramsci: "0 que é o homem? É esta a primeira e principal pergunta da filosofia. Como respondê-la? A definição pode ser encontrada no próprio homem, isto é, em cada homem singular» (Cad. 10, Parte II, § 54 GRAMSCI, 1999, p. 411).

O humano como ser genérico e indivíduo, se autoproduz nas relações que estabelece:

[...] deve-se conceber o homem como uma série de relações ativas (um processo), no qual, se a individualidade tem a máxima importância, não é todavia o único elemento a ser considerado. A humanidade que se reflete em cada individualidade é composta de diversos elementos: 1) o indivíduo; 2) os outros homens; 3) a natureza. [...]. 0 indivíduo não entra em relação com os outros homens por justaposição, mas organicamente, isto é, na medida em que passa a fazer parte de organismos [...] o homem não entra em relações com a natureza simplesmente pelo fato de ser ele mesmo natureza, mas ativamente, por meio do trabalho e da técnica. E mais: estas relações não são mecânicas. São ativas e conscientes [...] Daí ser possível dizer que cada um transforma a si mesmo, modifica-se, na medida em que transforma e modifica todo o conjunto de relações do qual ele é o centro estruturante. (Cad. 10, Parte II, § 54 - GRAMSCI, 1999, p. 413).

Todavia, o indivíduo não nasce e age em um mundo completamente criado por ele, pois herda a realidade produzida por outros, que lhe apresenta limites e possibilidades. De maneira que conhecer a herança histórica é fundamental para compreender o ser humano do presente, uma vez que é ser determinado pela história que produz. 0 presente é encontro do passado (herança da práxis pretérita) e do futuro (orientação à práxis, considerando a finalidade determinada pelos próprios sujeitos), que se desenvolve na totalidade concreta.

0 presente atuante não pode deixar de continuar, desenvolvendo-o, o passado, não pode deixar de estar inserido na "tradição". [...] É passado real, precisamente, a estrutura, já que ela é o testemunho, o "documento" incontroverso daquilo que foi feito e que continua a subsistir como condição do presente e do futuro. (Cad. 10, Parte II, § 59 - II - GRAMSCI, 1999, p. 422).

0 passado é herança que informa o presente e o futuro, que é possibilidade de ser, a se efetivar ou não pela práxis desenvolvida na situação presente, criando uma situação em que “[...] as circunstâncias fazem os homens tanto como os homens fazem as 
circunstâncias” (MARX; ENGELS, 1984, p. 49). Gramsci capta bem, isto é, dialeticamente, essa relação enunciada pelo marxismo originário e, assim, apresenta críticas a Benedeto Croce, pelo subjetivismo como princípio explicativo da história ${ }^{8}$, e a Giovanni Gentile - que se referencia naquele -, pelo "atualismo" que defende e que entende que é o "pensamento pensado’ que define a realidade (cf. Cad. 10, Parte I, § 7 - GRAMSCI, 1999, p. 294).

Para Gramsci, assim como para o marxismo originário, os humanos são "[...] reais, [definidos pela] sua ação e as suas condições materiais de vida, tanto as que encontraram como as que produziram" (MARX; ENGELS, 1984, p. 49). São ativos, autoproduzem-se na medida em que se articulam com os demais para garantirem a sobrevivência-existência, transformando a natureza e a si mesmos pela práxis que historicamente desenvolvem.

[...] ao colocarmos a pergunta "o que é o homem", queremos dizer: o que é que o homem pode se tornar, isto é, se o homem pode controlar seu próprio destino, se ele pode "se fazer", se pode criar sua própria vida. [...] o homem é um processo, precisamente o processo de seus atos. (Cad. 10, 1932 a 1935, Parte II, § 54 - GRAMSCI, 1999, p. 412).

Ainda pelo viés materialista de identificação do humano histórico-dialeticamente, Gramsci afirma ser ele "[...] um bloco histórico ${ }^{9}$ de elementos puramente subjetivos e individuais e de elementos de massa e objetivos ou materiais, com os quais o indivíduo ${ }^{10}$ está em relação ativa. Transformar o mundo exterior, as relações gerais, significa [...] desenvolver a si mesmo" (Cad. 10, Parte II, § 48 - GRAMSCI, 1999, p. 406). Logo, os humanos são seres que se autoproduzem. Não se deve crer na "[...] igualdade [de] redução do homem à categoria de história natural, indivíduo de uma espécie biológica, distinto não por qualificações sociais e históricas, mas por dotes naturais” (Cad. 10, § 35 - GRAMSCI, 1999, p. 350).

Seja na escola ou em processos educativos que se desdobram fora dela, é fato que "[...] toda geração educa a nova geração, isto é, forma-a; e a educação é a luta contra os instintos ligados às funções biológicas elementares, uma luta contra a natureza, a fim de dominá-la e de criar o homem ratualı à sua época" (Cad. 1, § 123 - GRAMSCI, 2000a, p. 62). Segundo essa concepção, não é uma opção ser ou não educado, pois a educação é inerente à humanidade. Assim, Gramsci não apresenta uma proposição sobre educação, mas a constatação histórica de que todo humano inexoravelmente é educado. É fato que os humanos sempre aprendem e ensinam-se a se tonarem humanos, embora o perfil desse ser varie com os contextos vividos.

Seja em que contexto for, é o ser humano que produz a própria natureza humana que o identifica, forma-se a si tal como é. Desta feita, é ser que se autoproduz, é ser de práxis. E por que é próprio do humano formar-se, isto é, educar-se? Porque não nasce pronto! Vem ao mundo inacabado, inconcluso e tem consciência da incompletude que o caracteriza como animal diferente dos demais. De modo que se dá o nome de educação

8- Cf. as críticas de Gramsci à história ético-política de Bendeto Croce, que sobrevaloriza o momento da direção política, do consenso como primordial no desenvolvimento histórico (Cad. 10, Parte I, § 7 - GRAMSCI, 1999, p. 293).

9- Para compreender o conceito de bloco histórico em Gramsci, recomenda-se cf. Portelli (1977).

10- Ragazzini formula uma teoria da personalidade em Gramsci, tomando como elemento interpretativo chave o conceito de bloco histórico (cf. RAGAZZINI, 2005). 
justamente ao processo histórico de completude do ser homem por si mesmo, de formação de si por si mesmo.

A propósito, essa concepção que entende “[...] a educação como imanente ao processo de produção do ser social” (MARTINS, 2017a, p. 255) identifica as teorias pedagógicas marxistas. Veja-se, por exemplo, que para marxistas da estatura de Dermeval Saviani,

Se a existência humana não é garantida pela natureza [...] mas tem de ser produzida pelos próprios homens, sendo, pois, um produto do trabalho, isso significa que o homem não nasce homem. Ele forma-se homem [...] necessita aprender a ser homem [...] a produção do homem é, ao mesmo tempo, a formação do homem, isto é, um processo educativo. A origem da educação coincide, então, com a origem do homem mesmo. (SAVIANI, 2007, p. 154).

Assim, é indispensável ao humano formar-se para garantir a própria existência, o que faz transformando a natureza e a si mesmo por um processo chamado trabalho, na acepção marxiana do termo. Por meio dele, o humano transforma a natureza, colocando-a à disposição de suas necessidades (os demais animais adaptam-se à natureza), e neste processo antecipa a ação pelo pensamento, projetando-se ao futuro (teleologia), do que resulta a modificação não apenas da natureza, mas também da própria natureza humana. Dito de outro modo, "[...] cada um transforma a si mesmo, [...] na medida em que transforma e modifica todo o conjunto de relações do qual ele é o ponto central» (Cad. 10, § 54 - GRAMSCI, 1999, p. 413).

Destaque-se que trabalho, no sentido aqui empregado, não pode ser confundido com emprego e isso tem repercussões importantíssimas, sobretudo, para a educação. Trabalho

[...] é um processo de que participam o homem e a natureza, processo em que o ser humano, com sua própria ação, impulsiona, regula e controla seu intercâmbio material com a natureza. Defronta-se com a natureza como uma de suas forças. Põe em movimento as forças naturais de seu corpo [...] a fim de apropriar-se dos recursos da natureza, imprimindo-lhes forma útil à vida humana [...] Uma aranha executa operações semelhantes às do tecelão, e a abelha supera mais de um arquiteto ao construir a colmeia. Mas o que distingue o pior arquiteto da melhor abelha é que ele figura na mente sua construção antes de transformá-la em realidade. No fim do processo do trabalho aparece um resultado que já existia antes idealmente na imaginação do trabalhador. (MARX, 1999, p. 211-212).

Emprego, por sua vez, é uma forma de garantir a existência em um tipo específico de modo de produção da vida social, como o capitalismo. A propósito, nas formações sociais antigas e feudais, a existência era garantida pela relação senhor-escravo e senhorservo respectivamente, ou seja, não existia a noção de emprego como concebida hoje. Essa concepção hodierna emergiu na modernidade com o modo de produção capitalista, no qual o emprego se desenvolveu associado à exploração econômica (extração da mais-valia) e à alienação a que as "classes subalternas"11 (do campo e das cidades) são submetidas.

11- Sobre o conceito de subalternidade em Gramsci, cf. Del Roio (2017). 
Na acepção marxista, verifica-se que trabalho não se reduz a emprego. Houve, há e poderá haver sociedade sem emprego, como, por exemplo, as formações sociais tradicionais, nas quais a existência é garantida pelo trabalho, mas nelas não há emprego. De outro modo, diz-se que não houve, não há e não haverá sociedade sem trabalho, pois este é, justamente, o conjunto de ações pelas quais a humanidade garante a existência. Caso deixe de existir o trabalho, inexistirá a própria humanidade.

Essa distinção é basilar à educação, porquanto assumido como princípio educativo o trabalho, o processo educacional terá um perfil, ou outro, caso se adote o emprego.

Da adoção do emprego como princípio educativo decorrem processos de ensinoaprendizagem voltados à formação de mão de obra ao mercado, como o que é preconizado pela pedagogia tecnicista ou mesmo por sistemas educativos duais, que impõem a dicotomia entre saber e fazer, entre trabalho intelectual e trabalho manual, oferecendo o saber à minoria privilegiada e apenas o fazer à maioria trabalhadora, o que Gramsci criticou (cf. MARTINS, 2000). Ao contrário, adotar o trabalho como princípio educativo implica o escopo de formação integral (teórica e prática) dos educandos, alcançada somente por processos educativos omnilaterais; é esse o fundamento da proposição educativa marxiana (cf. MARTINS, 2017a) e de marxistas como Gramsci, que a expressa na escola unitária.

Ao observar o desenvolvimento da história da humanidade, transformada radicalmente pelo trabalho, percebe-se que o ser humano se modificou sob vários pontos de vista: o modo de ser, de pensar, de agir e de sentir. A reflexão sobre esse processo indica que há sempre um ideal de ser humano diferente sendo forjado em cada contexto ou, dito de outra maneira, cada contexto exige um tipo específico de ser humano: na Grécia Antiga era o ser humano integral, forjado pela paideia; na Idade Média, o humano de fé; na modernidade, o humano racional, livre das crenças e tradições feudais. Assim sendo, o capitalismo tem também um ideal de humano, bem como o socialismo, e eles são efetivados em cada formação econômica e social por processos educativos específicos. As proposições educativas de Gramsci, como a escola unitária, contribuíram para a reflexão sobre como deve ser a escola que forma segundo o ideal de humano, que decorre do compromisso de superar o capitalismo e construir o socialismo.

Considerando que o ser humano é tensionado a ser formado de acordo com a correlação de forças sociais de cada contexto, a educação adquire evidente dimensão política e a política ganha dimensão educativa. Isso é claríssimo em Gramsci: a educação é política porque interage no processo de produção da humanidade em cada formação econômica e social; produz e difunde concepções de mundo, consolidando, combatendo ou propondo alternativas às hegemônicas; e a política manifesta nas sociedades ocidentais (formações econômicas e sociais onde o capitalismo mais se desenvolveu) tem clara dimensão educativa porque, para reproduzir ou transformar as relações sociais, é necessário educar as massas. Desta feita, para Gramsci, "Toda a relação de ‘hegemonia é necessariamente uma relação pedagógica” (Cad. 10 - Parte II, § 44 - GRAMSCI, 1999, p. 399).

Assim concebida a relação entre educação e política, de maneira imbricada, interdependente, interativa, intercomunicativa, isto é, dialética, a educação pode ser conservadora ou crítica. Quando consolida condições para a reprodução do tipo de civilização vigente, torna-se conservadora, e quando se contrapõe ao modelo de civilidade presente e lhe propõe alternativas, torna-se crítica. A concepção de escola em Gramsci 
é crítica, pois visa a construir as condições para que os educandos possam empreender a luta para superar a civilidade capitalista e edificar novas relações sociais, uma nova civilização, a socialista.

\section{A escola unitária em Gramsci}

As discussões de Gramsci sobre a escola estão mais desenvolvidas nos cadernos 1, 4, 12 e 22 produzidos no cárcere, segundo Manacorda (2013), bem como em algumas cartas. Observa-se neles que a proposição da escola unitária ${ }^{12}$ tem viés marxista, mas um marxismo atualizado à dinâmica do metabolismo social do capitalismo do século XX, cuja lógica de funcionamento é diferente do século anterior. A proposição escolar de Gramsci tem dois fundamentos e um compromisso, como toda proposta marxista deve ter: "[...] a) fundamentos: entender a educação como imanente ao devir do processo histórico de produção do ser social e assumir o trabalho como princípio educativo; b) compromisso: assumir a luta de classes como elemento articulador do processo educativo" (MARTINS, 2017a, p. 255).

Se educação é processo de formação humana, historicamente construiu-se um espaço para que ela se desenvolvesse, segundo o ideal de ser humano vigente no contexto: a escola.

Há diferentes tipos de escola e a unitária é uma proposição ao nível básico de ensino. Contudo, ela não nasceu pronta, amadureceu ao longo do tempo. Na juventude, até o chamado "Biênio Vermelho", Gramsci entendia que os processos de ensino-aprendizagem deveriam ser "desinteressados" (antônimo de "interesseiros", como se utiliza na linguagem corrente), isto é, uma formação geral do ser humano, propedêutica, democraticamente aberta a todos, não profissionalizante precocemente e sem a vinculação imediata com um modelo social específico. Contudo, nos escritos do cárcere, essa proposta educativa escolar amadureceu, fundou-se no trabalho como princípio educativo e adotou o objetivo de colaborar no processo de superação das relações sociais capitalistas, para construir uma nova civilização, favorecida pela escola como formadora de intelectuais.

Ao formular a escola unitária, Gramsci partiu da crítica às escolas do tempo por ele vivido, particularmente, a escola burguesa, a escola tradicional originária da Lei Casati, de 1859, e a advinda da reforma escolar fascista de Gentile, de 1922 e 1923.

Gramsci entendia a escola burguesa como "interesseira”, pois visava apenas a formar mão de obra, em benefício da burguesia. Todavia, reconhecia nela algumas qualidades: queria-se universal, priorizava a racionalização, caminho virtuoso para superar a concepção de mundo de mítica, folclórica ou de senso comum $^{13}$, e muitas delas adotavam o princípio da atividade entre educador e educando, estimulando o aprendizado.

Por sua vez, a escola tradicional emergiu na Itália com a Lei Casati, de 1859, que “[...] foi aplicada à Itália unida, [...] organizava o sistema escolar segundo princípios liberais: delineava uma administração centralizada [...], dividia a instrução escola em clássica e

12- Sobre a escola unitária, ver ainda Nosella (1992), Soares (2000), Manacorda (2013) e Martins (2017b).

13- Sobe o conceito de senso comum, recomenda-se cf. Debrum (2001). 
técnica” (CAMBI, 1999, p. 497). Assim constituída, era uma escola autoritária e distante dos dilemas sociais. Contudo, adotava, em geral, um currículo humanista centrado na transmissão do patrimônio histórico-cultural da humanidade às gerações futuras, algo que Gramsci reconhecia como importante a ser ensinado para as classes subalternas.

A escola da reforma de Gentile destinava instrução profissional e religiosa aos trabalhadores, para neles forjar a passividade ético-política; daí grande parte das críticas dirigidas a ela por Gramsci.

A partir desses posicionamentos, Gramsci começou a formular a escola unitária e se inspirou na reforma escolar russa, na "escola única do trabalho". Esse modelo foi incorporado ao programa do Partido Comunista Russo no $8^{\circ}$ Congresso (março-1919) e contava com o protagonismo de Krupskaia ${ }^{14}$, Lunatcharski ${ }^{15}$, Pistrak $^{16}$ e Shulgin ${ }^{17}$, pioneiros da revolucionária educação russa. A "escola única do trabalho" ansiava produzir uma nova cultura na Rússia, geral e politécnica, e um novo ser humano, com o desenvolvimento da mente, dos sentidos, do físico e da criatividade (estudados por precursores da escola nova) do novo sujeito que emergiu da Revolução de Outubro.

A escola unitária é a formulação mais madura de escola em Gramsci. Ela assume o ideal de formação integral do humano, um ser desenvolvido tão completamente quanto possível em relação às capacidades intelectuais e manuais, síntese do "[...] engenheiro americano, o filósofo alemão, o político francês, recriando [...] o homem italiano do Renascimento, o tipo moderno de Leonardo da Vinci transformado em homem-massa ou homem coletivo, ainda que mantendo sua forte personalidade [...] individual" (Carta a Júlia, 1/8/1932 - GRAMSCI, 2005, p. 225).

Como se observa, Gramsci desacreditava em natureza humana inata, em “dons naturais”, pois, para ele, o ser humano é produção humana. Isso fica claro quando afirma que:

[...] devo dizer que não acredito nestas inclinações genéricas tão precoces [...]. Acredito que, em cada um [...], coexistam todas as tendências, tal como em todas as crianças, tanto para a prática quanto para a teoria ou a fantasia, e que, de fato, seria correto guiá-los nesse sentido, para um ajuste harmonioso de todas as faculdades intelectuais e práticas, que podem se especializar no tempo apropriado, com base numa personalidade vigorosamente formada em sentido total e integral. (Carta a Júlia, 1/8/1932 - GRAMSCI, 2005, p. 224-225).

A formação integral preconizada pela escola unitária fornece aos educandos os elementos culturais mais desenvolvidos, forjados pela ciência, tecnologia, filosofia e arte, cuja síntese encontra-se nos clássicos de cada área. Ao se apropriarem desse patrimônio cultural produzido pela humanidade, poderá ocorrer a elevação do nível de consciência dos educandos, induzindo outro tipo de ação individual e coletiva, porque terão mais consciência de si e do mundo, condição basilar para formularem estratégias e promoverem ações com vistas a superar as contradições sociais que lhes desafiam a existência.

14 - Para conhecer uma introdução à concepção de educação em Krupskaia, cf. Lodi-Corrêa (2018).

15- Sobre Lunatcharski e a educação, cf. Prestes; Tunes (2017).

16 - Sobre este autor, cf., por exemplo, o livro Fundamentos da escola trabalho (PISTRAK, 2000).

17- Sobre Shulgin e a educação, cf. Freitas (2013). 
Desse modo, a escola unitária articula no mesmo processo de ensino-aprendizagem o saber e o fazer. 0 saber servirá ao propósito de se reconhecer, conhecer o mundo e os problemas nele presentes, daí a necessidade dos conhecimentos propedêuticos e humanísticos. Eles têm potencial de despertar a capacidade crítica e criativa dos educandos, e favorecer o desenvolvimento da personalidade individual com autonomia moral. Por sua vez, o fazer visa a capacitar educandos a operarem no mundo do trabalho, dominar o processo de produção social da existência, apropriando-se das habilidades e principalmente dos princípios científicos presentes nos aparatos tecnológicos das sociedades ocidentais. Assim sendo, estará o educando apto a se projetar no mundo do trabalho, não apenas com disciplina, mas com autodisciplina e racionalização, que são próprios do universo da moderna indústria.

A escola unitária, que é para o nível básico de ensino, recebe este nome, sobretudo, por três motivos: a) inspira-se na escola única do trabalho russa; b) é uma única escola para todos, universalizada - sem distinção pela condição econômica ou por qualquer outra -, pública, estatal, gratuita e laica, pois, para Gramsci, escola não pode ser privilégio; c) "A escola única [articula um único processo formativo], intelectual e manual" (Cad. 1, § 123 - GRAMSCI, 2000a, p. 63), diga-se, unitário. Guarda um método específico, conteúdos determinados e visa a uma precípua finalidade.

0 método da escola unitária se apresenta como o que descarta os dotes naturais e articula-se entre o espontaneísmo (seguindo os interesses do educando) e a autoridade, não o autoritarismo, porquanto ser o professor um sujeito que, no ambiente escolar, domina melhor os conteúdos escolares, sabe sobre o patrimônio científico, filosófico e artístico produzido pela humanidade, e tem compreensão mais elaborada sobre a realidade; assim, investe-se da condição de poder coordenar os trabalhos pedagógicos. No jogo didático entre educador e educando, a relação entre eles não deve ser de passividade, mas de atividade, respeitando, afetuosamente, o desenvolvimento físico, biológico e moral de cada educando. Assim sendo, nela deve haver intervenção do educador, que não é mero coadjuvante, mas protagonista, e como tal deve saber dosar mais intervenção no ponto de partida do processo educativo - leia-se: nas séries iniciais, quando a criança é mais imatura - e menos intervenção no ponto de chegada, pois os educandos já terão alcançado mais autonomia intelectual e moral, mais autodisciplina, podendo, então, gozar de mais liberdade, ou melhor, de menor intervenção dos educadores. Essa clara postura didática em favor do protagonismo docente é diferente da pedagogia nova (toma o professor como "mediador" ou "coordenador" dos trabalhos educativos), "[...] pois ao bel prazer, o discente se formará como ser caótico, síncrese das influências do ambiente” (MARTINS, 2017b, p. 1006). Além disso, em séries mais avançadas da escola unitária deverá haver o aprofundamento dos estudos, segundo Gramsci, com seminários e, no cotidiano, os educandos que sabem mais sobre determinado assunto deverão exercitar o apoio aos outros colegas, para que o coletivo escolar avance no aprendizado.

Em relação ao conteúdo, a escola unitária articula a formação intelectual-humanística tradicional (até mesmo com o estudo de grego e latim) e a moderna instrução tecnológica ao trabalho (MARTINS, 2007b, p. 1006), que se incorpora à dinâmica educativa: no nível fundamental de maneira indireta e implícita (domínio dos conhecimentos básicos para 
entender a dinâmica da vida concreta, produzida pelo trabalho humano) e no médio de modo explícito e direto, isto é, identificando como a ciência, potência imaterial, se incorpora na vida social com força produtiva (cf. SAVIANI, 2019). Isso exigirá completa reestruturação do ambiente escolar, com novos prédios, bibliotecas atualizadas, laboratórios e oficinas, e com um "[...] currículo escolar de vários níveis, de acordo com a idade e com o desenvolvimento intelectual e moral dos alunos» (GRAMSCI, Cad. 12, § 1 - 2000a, p. 36). Nesta escola, os alunos deverão se apropriar dos mais avançados conhecimentos de base racional (filosofia e ciências) e de noções estéticas (artes), que os possibilitem compreender a dinâmica de funcionamento da totalidade da vida social, para nela intervir. Pelos conteúdos das ciências naturais, os alunos poderão compreender a societas rerum, e pelas ciências sociais, a filosofia e as artes, a societas hominum, particularmente as "[...] noções dos direitos e deveres do cidadão" (GRAMSCI, Cad. 12, § 2 - 2000a, p. 42), de modo que possam superar "[...] a concepção mágica do mundo e da natureza, que a criança absorve do ambiente impregnado de folclore [...] e entra[r] em luta com as tendências à barbárie individualista e localista, que é também um aspecto do folclore" (Cad. 12, § 2 - GRAMSCI, 2000a, p. 42). E isso sem rebaixar o nível do ensino nas escolas que atendem as classes subalternas, pois acreditava Gramsci que se os subalternos tivessem condições adequadas, poderiam aprender o que a classe dominante aprendia, algo indispensável à construção de uma civilidade que atenda às suas necessidades, e não as do capital, encarnado nas relações sociais pela burguesia e pelos indivíduos e grupos sociais que ela conseguiu atrair para o seu bloco histórico ${ }^{18}$ por meio da hegemonia que conquistou. Assim concebida, a escola unitária “[...] fornece o ponto de partida para o posterior desenvolvimento de uma concepção histórica, dialética, do mundo, para a compreensão do movimento e do devir" (Cad. 12, § 2 - GRAMSCI, 2000a, p. 43).

A finalidade da escola unitária é habilitar sujeitos para lidarem com o mais avançado mundo do trabalho e formá-los desinteressadamente sob o ponto de vista ético-político, formá-los como intelectuais (cf. MARTINS, 2011) aptos a produzirem o exercício de uma nova hegemonia (cf. GRUPPI, 1978), até porque a "[...] escola é instrumento para elaborar intelectuais de diversos níveis" (Cad. 12, § 1 - GRAMSCI, 2000a, p. 19). Assim formados, esses sujeitos reuniriam condições a protagonizar o processo de construção de uma nova civilização, ou seja, romperiam com a indiferença política interessadamente produzida (Cad. 12, § 1 - GRAMSCI, 2000a, p. 15). A propósito, formar intelectuais ${ }^{19}$ é a precípua finalidade da escola unitária. Esse processo de formação desenvolvido pela escola unitária caminha na direção de uma cultura desinteressada, antisectária, historicista e humanista, mas visando a produção de uma nova civilização: "[...] ligada à vida [visa a] criar: os valores fundamentais do 'humanismo', a autodisciplina intelectual e a autonomia moral" (Cad. 12, § 2 - GRAMSCI, 2000, p. 45).

18- "A estrutura e as superestruturas formam um 'bloco histórico', isto é, o conjunto complexo e contraditório de superestruturas é o reflexo do conjunto das relações sociais de produção. [...] 0 raciocínio se baseia sobre a necessária reciprocidade entre estrutura e superestrutura" (Cad.8, $\S 182$ - GRAMSCI, 1999, p. 250-251).

19- Cf. o Caderno 12, dedicado aos intelectuais e também Máximo (2000) e Martins (2011). 
Se bem-sucedida, a escola unitária produzirá catarse ${ }^{20}$, isto é, formará nos sujeitos uma "segunda natureza" pela elevação do nível de consciência (do senso comum à consciência filosófica) sobre si e sobre o mundo, induzindo outro tipo de ação individual e coletiva. Ao forjar nos indivíduos a natureza humana não subalterna, contribuirá, sobremaneira, no processo de construção de uma nova civilização, pois serão sujeitos “[...] capaz[es] de pensar, de estudar, de dirigir e de controlar quem dirige" (Cad. 12, § 2 GRAMSCI, 2000a, p. 49).

Dessa forma concebida, a escola unitária não faz a revolução, mas é parte do processo de superação do capitalismo em sociedades ocidentais. É escola que "[...] reivindica [...] o dever do Estado de 'conformar' as novas gerações” (Cad. 12, § 1 - GRAMSCI, 2000a, p. 39).

\section{À guisa de conclusão}

Considerando os limites deste texto, apenas duas inferências serão destacadas a partir do que foi exposto, deixando as demais ao livre exercício reflexivo dos leitores.

A primeira delas diz respeito à leitura dos textos de Gramsci. Como antes mencionado, aqui é reafirmado que a melhor forma de se ler os textos gramscianos, abertos e assistemáticos, é buscar na vida de militante político e sindical a chave interpretativa da totalidade de produção teórica que teve, sobretudo, na obra de maturidade, os "Cadernos do cárcere". Evita-se, assim, interpolações estranhas ao que foi o militante comunista italiano. Ao ler os cadernos desse modo, perceber-se-á que o conceito-chave à interpretação do legado de Gramsci reside na práxis, por isso, inclusive, a própria filosofia ${ }^{21}$ ele mesmo definiu como "filosofia da práxis", reportando-se ao legado do marxismo originário (Cad. 12, § 1 - GRAMSCI, 2000a, p. 16).

A segunda observação diz respeito à práxis de Gramsci, que se preocupou com a educação e com a cultura no processo de luta por superar o capitalismo e produzir uma nova civilização na Itália. 0 italiano tem uma posição muito clara, evidenciada em seus textos e na práxis que desenvolveu: para as classes subalternas superarem o capitalismo e produzirem relações sociais que lhes interessa como classe, é necessário reeducar-se e a escola unitária é um instrumento para tanto. De maneira que, segundo o prisma gramsciano, é possivel dizer que a revolução no contexto atual também é um problema da educação.

Assim concebida a educação e a escola em Gramsci, infere-se que elas são, de fato, uma continuidade atualizada do legado do marxismo originário, as quais, nas formulações de Marx e Engels, não se encontram de maneira completamente sistematizada.

\section{Referências}

BIANCHI, Álvaro. 0 laboratório de Gramsci: filosofia, história e política. São Paulo: Alameda, 2008.

20- "[...] pode-se empregar a expressão 'catarse' para indicar a passagem do momento meramente econômico (ou egoístico-passional) ao momento ético-político, isto é, a elaboração superior da estrutura em superestrutura na consciência dos homens." (Cad. 10, § 6, GRAMSCI, 1999, p. 314).

21- Em relação à discussão sobre a filosofia em Gramsci, recomenda-se cf., entre outros, Martins (2013). 
BUCI-GLUCKSMANN, Christinne. Gramsci e o estado. Trad. de Angelina Peralva, 2. ed. Rio de Janeiro: Paz e Terra, 1980.

CAMBI, Franco. História da pedagogia. Trad. de Álvaro Lorencini. São Paulo: Unesp, 1999. (Encyclopaidéia). COUTINHO, Carlos Nelson. Gramsci: um estudo sobre seu pensamento político. Rio de Janeiro: Civilização Brasileira, 1999.

DEBRUM, Michel. Gramsci: filosofia, política e bom senso. Campinas: Unicamp: Centro de Lógica e Epistemologia, 2001.

DEL ROIO, Marcos (org.). Gramsci: periferia e subalternidade. São Paulo: Edusp, 2017.

DIAS, Edmundo Fernandes. Gramsci em Turim: a construção do conceito de hegemonia. 1. ed. São Paulo: Xamã, 2000. (Idéia \& ação).

FIORI, Giuseppe. A vida de Antonio Gramsci. Rio de Janeiro: Paz e Terra, 1979.

FRANCIONI, Gianni. L'officina gramsciana: ipotesi sulla struttura de"Quaderni del cárcere". Nápoles: Bibliopolis, 1984.

FREITAS, Luiz Carlos de. Prefácio. In: SHULGIN, Viktor Nikholaevich. Rumo ao politecnismo: artigos e conferencias. São Paulo: Expressão Popular, 2013. p. 7-11.

GALASTRI, Leandro. Gramsci, marxismo e revisionismo. Campinas: Autores Associados, 2015. (Educação contemporânea).

GRAMSCI, Antonio. Cadernos do cárcere: Antonio Gramsci: introdução ao estudo da filosofia; a filosofia de Benedetto Croce. Edição e tradução de Carlos Nelson Coutinho; co-edição de Luiz Sérgio Henriques e Marco Aurélio Nogueira. v. 1. Rio de Janeiro: Civilização Brasileira, 1999.

GRAMSCI, Antonio. Cadernos do cárcere: Antonio Gramsci: os intelectuais; o princípio educativo; jornalismo. Edição e tradução de Carlos Nelson Coutinho; co-edição de Luiz Sérgio Henriques e Marco Aurélio Nogueira. v. 2. Rio de Janeiro: Civilização Brasileira, 2000a.

GRAMSCI, Antonio. Cadernos do cárcere: Antonio Gramsci: Maquiavel; notas sobre o Estado e a política. Edição e tradução de Carlos Nelson Coutinho; co-edição de Luiz Sérgio Henriques e Marco Aurélio Nogueira. v. 3. Rio de Janeiro: Civilização Brasileira, 2000b.

GRAMSCI, Antonio. Cartas do cárcere (1931-1937). Tradução de Luiz Sérgio Henriques. v. 2. Rio de Janeiro: Civilização Brasileira, 2005.

GRUPPI, Luciano. 0 conceito de hegemonia em Gramsci. Tradução de Carlos Nelson Coutinho e apresentação de Luiz Werneck Vianna. 2. ed. Rio de Janeiro: Graal, 1978.

JESUS, Antônio Tavares de. 0 pensamento e a prática escolar de Gramsci. Campinas: Autores Associados, 2005. 
LEPRE, Aurélio. 0 prisioneiro: a vida de Antonio Gramsci. Rio de Janeiro: Record, 2001.

LODI-CORRÊA, Samantha. Nadezhda Krupskaia: por uma educação revolucionária. Germinal, Salvador, v. 10, n. 3, p. 236-244, dez. 2018. Disponível em: https://periodicos.ufba.br/index.php/revistagerminal/ article/view/27387. Acesso em: 4 mar. 2021.

MAESTRI, Mário; CANDREVA, Luigi. Antonio Gramsci: vida e oba de um comunista revolucionário. São Paulo: Expressão Popular, 2001.

MANACORDA, Mario Alighiero. 0 princípio educativo em Gramsci. 2. ed. Campinas: Alínea, 2013.

MARTINS, Marcos Francisco. Ensino técnico e globalização: cidadania ou submissão? Campinas: Autores Associados, 2000. (Polêmicas de nosso tempo; v. 71).

MARTINS, Marcos Francisco. Gramsci, filosofia e educação. Práxis Educativa, Ponta Grossa, v. 8, n. 1, p. 13-40, jan./jun. 2013. Disponível em: http://www.revistas2.uepg.br/index.php/praxiseducativa/article/ view/5369. Acesso em: 28 dez. 2018.

MARTINS, Marcos Francisco. Gramsci, os intelectuais e suas funções científico-filosófica, educativocultural e política. Pro-Posições, Campinas, v. 22, n. 3 (66), p. 131-148, set./dez. 2011. Disponível em: http://www.scielo.br/pdf/pp/v22n3/10.pdf. Acesso em: 02 jan. 2019.

MARTINS, Marcos Francisco. Marx e Engels: apontamentos sobre educação. Comunicações, Piracicaba, v. 24, n. 2, p. 247-266, maio/ago. 2017a. Disponível em: https://www.metodista.br/revistas/revistas-unimep/ index.php/comunicacoes/article/view/2869/1959. Acesso em: 12 jan. 2019.

MARTINS, Marcos Francisco. Sociedade civil e "Terceiro Setor": apropriações indébitas do legado teóricopolítico de Gramsci. Revista de Filosofia Aurora, Curitiba, v. 20, n. 26, p. 75-100, jan./jun. 2008. Disponível em: https://periodicos.pucpr.br/index.php/aurora/article/view/1462/1393. Acesso em: 01 jul. 2019.

MARTINS, Marcos Francisco. "Tradução" da escola unitária de Gramsci pela pedagogia histórico-crítica de Saviani. ETD - Educação Temática Digital. Campinas, v. 20, n. 4, p. 997-1017. out./dez. 2017b. Disponível em: https://periodicos.sbu.unicamp.br/ojs/index.php/etd/article/view/8649915. Acesso em: 23 maio 2019.

MARX, Karl. 0 capital: crítica da economia política. Tradução de Reginaldo Sant'Ana. 17. ed. Rio de Janeiro: Civilização Brasileira, 1999.

MARX, Karl; ENGELS, Friedrich. A ideologia alemã: $1^{\circ}$ capítulo seguido das teses sobre Feuerbach. São Paulo: Moraes, 1984.

MAXIMO, Antonio Carlos. Os intelectuais e a educação das massas. Campinas: Autores Associados, 2000. (Polêmicas do nosso tempo; v. 76).

NOSELLA, Paolo. A escola de Gramsci. Porto Alegre: Artes Médicas Sul, 1992.

PISTRAK, Moisey Mikhaylovich. Fundamentos da escola do trabalho. Tradução de Daniel Aarão Filho. São Paulo: Expressão Popular, 2000. 
PORTELLI, Hugues. Gramsci e o bloco histórico. Tradução de Angelina Peralva. Rio de Janeiro: Paz e Terra, 1977. (Pensamento crítico; v. 7).

PRESTES, Zoia; TUNES, Elizabeth. Anatoli Vassilievitch lunatcharski e os princípios da escola soviética. Movimento, Niterói, v. 4, n. 6, p. 254-271, jan./jun. 2017. Disponível em: https://periodicos.uff.br/ revistamovimento/article/view/32599/18734. Acesso em: 29 out. 2020.

RAGAZZINI, Dario. Teoria da personalidade na sociedade de massa: a contribuição de Gramsci. Tradução de Maria de Lourdes Menon. Campinas: Autores Associados, 2005.

SAVIANI, Dermeval. Entrevista com o professor Dermeval Saviani - a pedagogia histórico-crítica na atualidade. Colloquium Humanarum, Presidente Prudente, v. 16, n. 2, p. 4-12, abr./jun. 2019. Disponível em: http://revistas.unoeste.br/index.php/ch/article/view/3121. Acesso em: 01 jul. 2019.

SAVIANI, Dermeval. Trabalho e educação: fundamentos ontológicos e históricos. Revista Brasileira de Educação, Rio de Janeiro, v. 12, n. 34, jan./abr. 2007. Disponível em: http://www.scielo.br/pdf/rbedu/ v12n34/a12v1234.pdf. Acesso em: 10 jan. 2019. p. 152-180.

SEMERARO, Giovanni. Gramsci e a sociedade civil: cultura e educação para a democracia. Petrópolis, Vozes, 1999.

SOARES, Rosemary Dore. Gramsci, o Estado e a escola. ljuí: Unijuí, 2000. (Educação).

Recebido em: 15.07.2019

Revisado em: 26.08.2019

Aprovado em: 10.09.2019

Marcos Francisco Martins é professor associado da Universidade Federal de São Carlos (UFSCar), campus Sorocaba, licenciado em filosofia, mestre e doutor em educação, líder do Grupo de Pesquisa Teorias e Fundamentos da Educação (GPTeFE) e bolsista PQ-CNPq. 